\title{
A computational study on the sources of deuterium secondary kinetic isotope effects in carbocation-forming reactions
}

\author{
Heidi M. Muchall and Nick H. Werstiuk
}

\begin{abstract}
Calculations at the HF-DFT hybrid Becke3LYP level of theory have been undertaken on protonated 2-exoand 2-endo-norbornanols as model substrates for 2-exo- and 2-endo-norbornyl brosylates to explore the source of the experimentally determined deuterium secondary kinetic isotope effects (KIEs). Calculations on protonated alcohols as models reproduce the "normal" behaviour of 2-endo substrate 5. The observed endo $\gamma$-KIE in the 7-unsubstituted 2-exo system $\mathbf{4}$ is shown to arise from internal return, while those in the 7-chloro substituted 2-exo substrates $\mathbf{1}$ and $\mathbf{2}$ can be explained with competing 1,3 (6,2)-elimination.
\end{abstract}

Key words: deuterium secondary kinetic isotope effects, 2-norbornyl cation, Becke3LYP.

Résumé : Utilisant les formes protonées des 2-exo- et 2-endo-norbornanols comme modèles des brosylates des 2-exoet 2-endo-norbornyles, on a effectué des calculs au niveau théorique hybride Becke3LYP HF-DFT afin d'explorer la source des effets isotopiques cinétiques (EIC) secondaires du deutérium observés expérimentalement. Les calculs sur les alcools protonés utilisés comme modèles permettent de reproduire le comportement "normal » du substrat 2-endo (5). On a démontré que l'EIC- $\gamma$ endo observé dans le système 2-exo non substitué en position 7 (4) découle d'un retour interne alors que l'on peut expliquer ceux observés avec les substrats 2-exo substitués par un chlore en position 7 ( 1 et 2 ) en invoquant une réaction d'élimination-1,3 (6,2) compétitive.

Mots clés : effets isotopiques cinétiques secondaires du deutérium, cation 2-norbornyle, Becke3LYP.

[Traduit par la Rédaction]

Deuterium secondary kinetic isotope effects (KIEs) have been used for decades to gain information on reaction intermediates and transition states, which forms the basis of widely used structure-reactivity principles. Representative of these studies is the work of Werstiuk et al. on 1-OBs and 2-OBs (1) and 3 (2), which was undertaken to probe the degree of $\mathrm{C}^{6}-\mathrm{C}^{1}$ participation in the cation-forming step of the solvolysis reactions in NaOAc-buffered 80:20 EtOH- $\mathrm{H}_{2} \mathrm{O}$.

Earlier it was shown that exo-2-norbornyl brosylate-exo6- $d$ (4-OBs6ex) and exo-2-norbornyl brosylate-endo-6- $d$ (4-OBs6en) exhibit unusually large $\gamma$-KIEs (4-OBs6ex: 9\%, 4-OBs6en: $11 \%$ ), and the results were interpreted on the basis of a $\mathrm{C}^{6}-\mathrm{C}^{1}$ bond assistance in the solvolyses $\left(k_{\Delta}, \mathrm{X}=\mathrm{H}\right)$ (3) (Scheme 1). While endo-2-norbornyl brosylate-exo-6-d (5-OBs6ex) did not exhibit a $\gamma$-KIE, that of endo-2-norbornyl brosylate-endo-6- $d$ (5-OBs6en) was slightly inverse

Received October 27, 1998.

H.M. Muchall ${ }^{1}$ and N.H. Werstiuk. ${ }^{1}$ Department of Chemistry, McMaster University, Hamilton, ON L8S 4M1, Canada.

${ }^{1}$ Authors to whom correspondence may be addressed. Telephone: (905) 525-9140. Fax: (905) 522-2509.

E-mail: muchall@mcmaster.ca; werstiuk@mcmaster.ca<smiles>[R]C1C([X])C2CC3C1CC3C2([R])[R]</smiles>

$\mathrm{L}=\mathrm{OBs}, \mathrm{OH}_{2}^{+}$

$\begin{array}{llllll}\mathrm{R}^{1} & \mathrm{R}^{2} & \mathrm{R}^{3} & \mathrm{X} & \mathrm{X}^{\prime} & \mathrm{R}=\mathrm{H}, \mathrm{D}\end{array}$

$\begin{array}{llllll}\text { 1-5ex6ex } & H & \text { D } & \text { D } & \text { Cl } & H\end{array}$

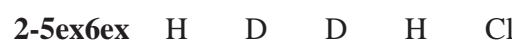

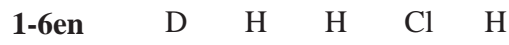

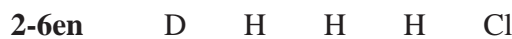

(3\%). Similar results were obtained from acetolysis reactions (4). It was reasoned that a strong electron-withdrawing substituent at $\mathrm{C}^{1}$ or $\mathrm{C}^{7}$ should reduce the contribution of the $k_{\Delta}$ process (1), as the build up of a partial positive charge on $\mathrm{C}^{1}$ would become less favourable.

Unexpectedly, $\gamma$-KIEs in anti- and syn-7-chloro-exo-2-norbornyl brosylate-exo,exo-5,6- $d_{2}$ (1-OBs5ex6ex: 15\%, 2OBs5ex6ex: 12\%) and anti- and syn-7-chloro-exo-2-norbornyl brosylate-endo-6-d (1-OBs6en: 12\%, 2-OBs6en: 13\%) were found to be larger than those found for the parent exo substrate 4-OBs. This was interpreted with a combination of ef- 


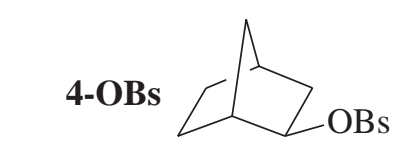<smiles>[2H]C1CC2CC([2H])C1C2</smiles><smiles>[2H]C1CC2CC([B])C1C2</smiles>

4-OBs6ex<smiles>OCC1CC2CC1CC2O[SbH2]</smiles><smiles>[R9]C1CC2CC([2H])C1C2</smiles>

5-OBs6ex 5-OBs6en
Scheme 1.

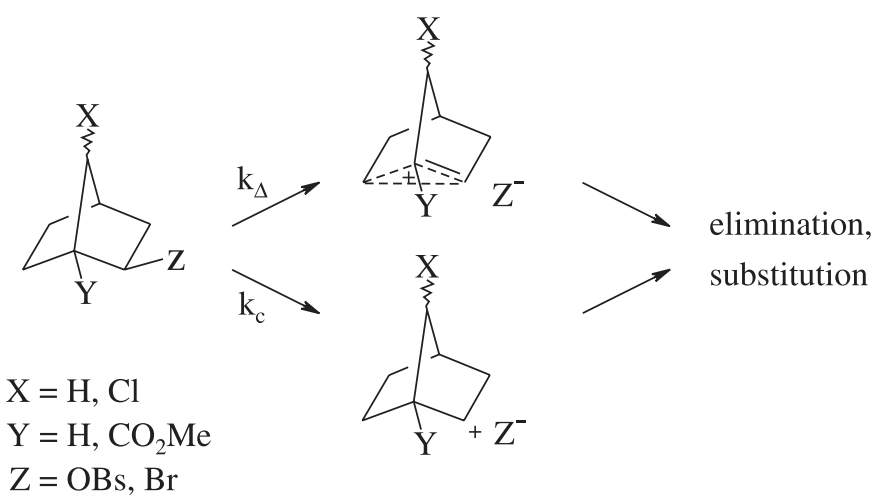

fects instead of a simple $\mathrm{C}^{6}-\mathrm{C}^{1}$ bond participation (considered were 1,3 elimination, endo hydrogen participation, 6,2-hydride shift, and solvent-assisted ionization), yet a final clarification was not achieved (1). Moreover, the unusually large $\gamma$-KIE found for bromoester 3 exhibited a solvent-polarity dependence (14\% in $0.09 \mathrm{M} \mathrm{NaOAc}$ buffered 80:20 EtOH $-\mathrm{H}_{2} \mathrm{O}$ and $20 \%$ in $0.14 M$ NaOAc buffered $\left.80: 20 \mathrm{EtOH}-\mathrm{H}_{2} \mathrm{O}\right)(2)$. While the authors $(1-4)$ drew conclusions from the experimental data (KIEs, products) and from analogous reactions, definitive statements could not be made at that time. Today, the full force of quantum chemical calculations can be brought to bear on problems of this type to gain fundamental information not directly accessible experimentally and, as a result, provide definitive solutions (see, for example, ref. 5). In this communication, we report the results of a computational study (using Gaussian 94 (6)) of deuterium secondary KIEs of systems $\mathbf{1 , 2 , 4}$, and $\mathbf{5}$.

As the brosylate systems are prohibitively large, it was necessary to find a reasonable level of theory as well as suitable model systems for substrates and solvolysis transition states. The problems in describing the 2-norbornyl cation are well known and have been confirmed by a computational study by Schleyer and co-workers (7): the classical 2norbornyl cation (7) is a transition state in the rearrangement from the 2-norpinyl cation (6) to the - what so far has been referred to as "nonclassical" - 2-norbornyl cation (8); this result was achieved at the MP2(full)/6-31G(d) level of theory that was termed "adequate" because 7 was found not to be a stationary point at the $\mathrm{HF} / 6-31 \mathrm{G}(\mathrm{d})$ level. In a more recent paper it is stated that a similar structure for 7 could be calculated using Becke3LYP/6-31G(d) (8). Our excellent experiences with the HF-DFT hybrid theory Becke3LYP (9) for different systems and chemical problems (10) led us to employ the computationally quite inexpensive Becke3LYP/ $6-31 \mathrm{G}(\mathrm{d}, \mathrm{p})$ level of theory, ${ }^{2}$ the inclusion of polarization functions on the hydrogen atoms being essential for the intended study of deuterium KIEs. We found that the 2-norbornyl cation can be described adequately at this level of theory: transition state 7 exhibits the one desired imaginary frequency $\left(-266.6 \mathrm{~cm}^{-1}\right)$ and an IRC calculation links 7 to $\mathbf{6}$ and 8. According to Becke3LYP/6-31G(d,p), 7 lies $13.17 \mathrm{kcal}$ mol $^{-1}$ above $8,{ }^{3}$ which is in excellent agreement with the $13.64 \mathrm{kcal} \mathrm{mol}^{-1}$ found with MP4(sdq,fc)/6-31G (d,p)//MP2 (full)/6-31G(d) $\left(13.1 \mathrm{kcal} \mathrm{mol}^{-1}\right.$ with Becke $3 \mathrm{LYP} / 6-311+\mathrm{G}(\mathrm{d})$ (8)) reported by Schleyer and co-workers $(7 a)$. We therefore carried out geometry optimizations as well as frequency calculations using Becke3LYP/6-31G(d,p).

We assumed ${ }^{4}$ that an optimized protonated alcohol is a good model for a reactant with the neutral leaving group water forcing the positive charge onto the hydrocarbon fragment in the transition state for dissociation. To test this approach, we calculated secondary $\alpha$ - and $\beta$-KIEs for a "normal" system, cyclopentyl brosylate (9-OBs). The KIE is computed as the ratio of the rate constant for the undeuterated (light) species over that for the deuterated (heavy) one. Secondary KIEs were determined with the program MacIEcalc ${ }^{5}$ from masses, moments of inertia, and frequencies of light and heavy reactants as well as light and heavy transition states (TS) with the temperature set at $298.15 \mathrm{~K}$ if not stated otherwise. As scaling factors for Becke3LYP calculations are very close to 1.0 , frequencies were not scaled (11); secondary KIEs do not require correction for a tunneling effect. A transition state for the dissociation of the protonated cyclopentanol could not be located, but computed KIEs using models for the TS, in which the $\mathrm{C}-\mathrm{O}$ distance in the protonated alcohol is fixed at either 210 or $250 \mathrm{pm}$, were compared to experimental ones as determined by Stoffer and Christen (12) (KIEs in Table 1). With the 210

${ }^{2}$ See refs. $5 a$ and $b$; in these papers, Houk and co-workers conclude that Becke3LYP calculations provide good predictions of KIEs.

${ }^{3}$ Zero-point energy uncorrected total energies are -273.060433 hartrees for $\mathbf{7}$ and -273.081420 for $\mathbf{8}$.

${ }^{4}$ This work was started before ref. 8 was available.

${ }^{5}$ K. Korzekwa, J. Urbauer, D. Kiick, and J. Jones (changes by W.H. Saunders). University of Rochester, Rochester, N.Y. 
Table 1. Experimental and calculated $\alpha-, \beta$-, and $\gamma$-KIEs for $\mathbf{1}, \mathbf{2}, \mathbf{4}, \mathbf{5}$, and $\mathbf{9}$. Calculations employ the transition state (TS, with C-O distances as given in Fig. 1) and 180, 210, and 310 pm models of the protonated alcohols.

\begin{tabular}{|c|c|c|c|c|c|c|}
\hline & \multirow[b]{2}{*}{ Deuterium position } & \multirow[b]{2}{*}{ Expt. $^{a}$} & \multicolumn{4}{|c|}{ Model } \\
\hline & & & $\mathrm{TS}$ & $180 \mathrm{pm}$ & $210 \mathrm{pm}$ & $310 \mathrm{pm}$ \\
\hline $1-5 \mathrm{ex} 6 \mathrm{ex}$ & $\gamma, \delta$ & $1.150 \pm 0.013^{b}$ & 1.166 & & 1.082 & \\
\hline 1-6en & $\gamma$ & $1.120 \pm 0.005^{b}$ & 1.064 & & 1.003 & \\
\hline $2-5 \operatorname{ex} 6 \mathrm{ex}$ & $\gamma, \delta$ & $1.119 \pm 0.011^{b}$ & $1.131^{c}$ & & 1.045 & \\
\hline 2-6en & $\gamma$ & $1.125 \pm 0.007^{b}$ & $1.028^{c}$ & & 1.001 & \\
\hline 4-6ex & $\gamma$ & $1.09 \pm 0.01^{d}$ & 1.127 & 1.015 & 1.051 & 1.130 \\
\hline 4-6en & $\gamma$ & $1.11 \pm 0.01^{d}$ & 1.054 & 0.999 & 0.998 & 1.045 \\
\hline 4-3en3ex & $\beta, \beta$ & $1.10^{e, f}$ & $1.066^{f}$ & $1.037^{f}$ & $1.113^{f}$ & $1.106^{f}$ \\
\hline $4-5 \operatorname{ex} 6 \mathrm{ex}$ & $\gamma, \delta$ & $1.09^{g}$ & 1.126 & 1.017 & 1.053 & 1.132 \\
\hline $5-6 e x$ & $\gamma$ & $1.00 \pm 0.02^{d, h}$ & $1.015^{h}$ & & $0.997^{h}$ & \\
\hline 5-6en & $\gamma$ & $0.97 \pm 0.01^{d, h}$ & $0.949^{h}$ & & $0.969^{h}$ & \\
\hline $5-2 e x$ & $\alpha$ & $1.20^{h, i}$ & $1.203^{h}$ & & $1.144^{h}$ & \\
\hline 5-3en3ex & $\beta, \beta$ & $1.26^{j, k}$ & $1.285^{k}$ & & $1.141^{k}$ & \\
\hline $5-5 \operatorname{ex} 6 \mathrm{ex}$ & $\gamma, \delta$ & $1.00^{f, k}$ & $1.015^{k}$ & & $0.993^{k}$ & \\
\hline 9 & $\alpha$ & $1.187^{l}$ & & & $1.148(1.238)^{m}$ & \\
\hline 9 & $\beta$-cis & $1.153^{l}$ & & & $1.053^{n}(1.161)^{m, o}$ & \\
\hline 9 & $\beta$-trans & $1.180^{l}$ & & & $1.141^{p}(1.206)^{m, q}$ & \\
\hline 9 & $\beta^{r}$ & $1.888^{l}$ & & & $1.443(1.959)^{m}$ & \\
\hline
\end{tabular}

${ }^{a}$ For the brosylates.

${ }^{b}$ Reference 1 .

${ }^{c}$ For the 290 pm model.

${ }^{d}$ Reference 3 .

${ }^{e}$ Reference 13 .

${ }^{f}$ At $317.45 \mathrm{~K}$.

${ }^{g}$ Reference 14 .

${ }^{h}$ At $323.15 \mathrm{~K}$.

${ }^{i}$ Reference 15.

${ }^{j}$ Reference 16.

${ }^{k}$ At $338.15 \mathrm{~K}$.

${ }^{l}$ Reference 12.

${ }^{m}$ For the 250 pm model.

${ }^{n}$ From 1.093 and 1.015 for nonequivalent positions 2 and 5 .

${ }^{o}$ From 1.039 and 1.297 for nonequivalent positions 2 and 5 .

${ }^{p}$ From 1.073 and 1.214 for nonequivalent positions 2 and 5 .

${ }^{q}$ From 1.059 and 1.374 for nonequivalent positions 2 and 5.

r2,2,5,5-Tetrasubstitution.

pm model, all calculated KIEs for 9 are smaller than the experimental values, while all are slightly too large at $250 \mathrm{pm}$.<smiles>CCCCCCCCCCCCC</smiles>

9-OBs<smiles>[2H]C1CCCC1[OH2+]</smiles>

$\beta$-cis

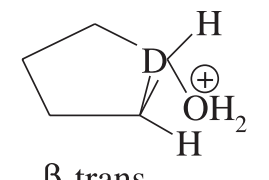

$\beta$-trans
These results suggest that the $\mathrm{C}-\mathrm{O}$ distance in the TS lies between 210 and $250 \mathrm{pm}$, providing support for our choice of model.

The located transition-state geometries ${ }^{6}$ for $\mathbf{4}-\mathbf{O H}_{2}{ }^{+}$and

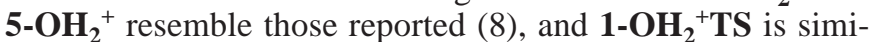
lar to $\mathbf{4 - \mathbf { O H } _ { 2 }}{ }^{+} \mathbf{T S}$ (so far we have not been successful in locating the transition state for the syn-7-chloro-exo-2-nor- bornyl brosylate (2), but a model with the $\mathrm{C}-\mathrm{O}$ distance at $290 \mathbf{~ p m}$ was taken as an approximation to $\mathbf{2 - \mathbf { O H } _ { 2 }}{ }^{+} \mathbf{T S}$ ). The hydrocarbon fragment in each transition state is distinctly unsymmetrical as can be seen from the $\mathrm{C}^{6}-\mathrm{C}^{1}$ and $\mathrm{C}^{6}-\mathrm{C}^{2}$ distances given in Fig. 1, and even though the exo transition states $\mathbf{1 - \mathbf { O H } _ { 2 }}{ }^{+} \mathbf{T S}$ and $\mathbf{4 - \mathbf { O H } _ { 2 }}{ }^{+} \mathbf{T S}$ are closer to being symmetrical than the endo transition state $\mathbf{5 - \mathbf { O H } _ { 2 }}{ }^{+} \mathbf{T S}$, it is important to note that all three hydrocarbon cation moieties are classical, contrary to the interpretation of Schleyer and co-workers (8); a situation that is emphasized in Fig. 1 by

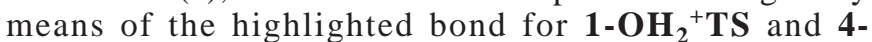
$\mathbf{O H}_{2}{ }^{+}$TS. The topology of the charge density of the 2norbornyl cation that has been moved from $C_{S}$ symmetry as determined in an atoms in molecules (17) study shows a $(3,-1)$ or bond critical point only between $\mathrm{C}^{6}$ and $\mathrm{C}^{1}$, not between $\mathrm{C}^{6}$ and $\mathrm{C}^{2}$, and confirms the classical character of every struc-

${ }^{6}$ Zero-point energy uncorrected total energies are $-809.111584\left(\mathbf{1}-\mathbf{O H}_{2}{ }^{+}\right),-809.102719\left(\mathbf{1 - O H}{ }^{+} \mathbf{T S}\right),-809.129369\left(\mathbf{2}-\mathbf{O H}_{2}{ }^{+}\right),-349.527681$ $\left(\mathbf{4 - O H}{ }^{+}\right),-349.518000\left(\mathbf{4}-\mathbf{O H}_{\mathbf{2}}{ }^{+} \mathbf{T S}\right),-349.524206(\mathbf{5})$, and -349.512550 hartrees $\left(\mathbf{5}-\mathbf{O H}_{\mathbf{2}}{ }^{+} \mathbf{T S}\right)$. 
Fig. 1. Transitions states (TS) for the loss of water from protonated alcohols $\mathbf{1}-\mathbf{O H}_{2}{ }^{+}, \mathbf{4}-\mathbf{O H}_{\mathbf{2}}{ }^{+}$, and $\mathbf{5}-\mathbf{O H}_{\mathbf{2}}{ }^{+}$with $\mathrm{C}-\mathrm{C}$ and $\mathrm{C}-\mathrm{O}$ distances in $\mathrm{pm}$. See text for the highlighted bond.
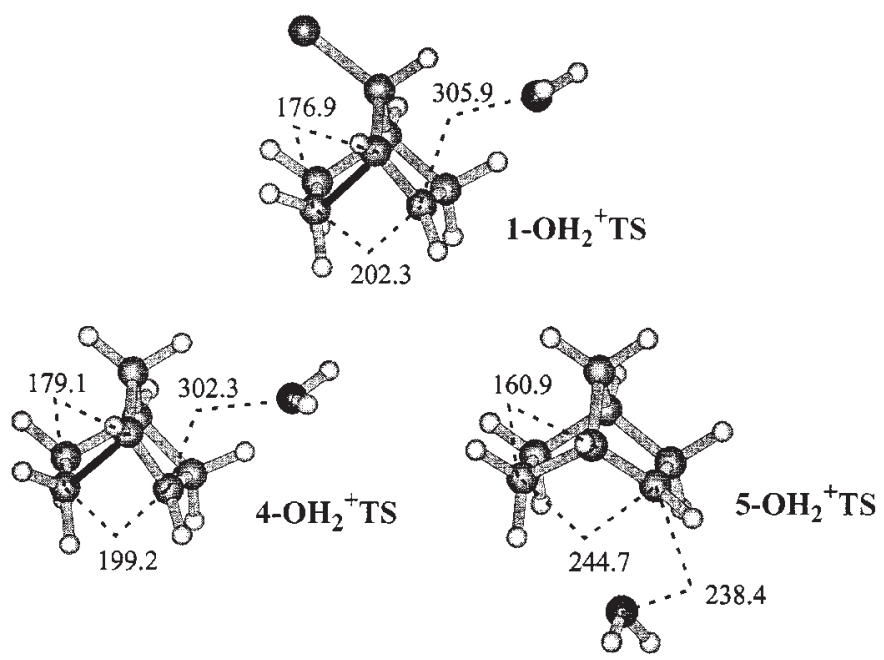

Scheme 2.<smiles>OCC1C2CC(C1O)C(O)(Cl)C2</smiles><smiles>CCC(C)C</smiles><smiles>OC1CC2CC(C1O)C(O)[C@H]2O</smiles>

180,210 , or $310 \mathrm{pm}$

ture but the $C_{S}$ symmetrical one - which is a $\pi$-complex, as was suggested earlier by Dewar et al. (18)! A communication reporting these results has been submitted (19).

To gain some further insight into the source of the KIEs, the transition states were also modelled by fixing the $\mathrm{C}-\mathrm{O}$ bond in the protonated alcohol at an appropriate value (we chose $210 \mathrm{pm}$ ) and optimizing the resulting system. These pseudo-transition states, just as the true gas-phase transition states, show one imaginary frequency that has the expected dispositions. Additionally, we performed calculations for 180 and $310 \mathrm{pm} \mathrm{C}-\mathrm{O}$ distances in $\mathbf{4 - \mathbf { O H } _ { 2 }}{ }^{+}$. The absolute value of the imaginary frequency is largest for the $210 \mathrm{pm}$ model of $\mathbf{4 - \mathbf { O H } _ { 2 }}{ }^{+}\left(-120.1 \mathrm{~cm}^{-1}\right)$; it is considerably smaller for the $310 \mathrm{pm}$ model $\left(-45.7 \mathrm{~cm}^{-1}\right)$ and for $\mathbf{4 - O \mathbf { H } _ { 2 } { } ^ { + } \mathbf { T S }}$ $\left(-51.3 \mathrm{~cm}^{-1}\right)$ and nonexistent in the $180 \mathrm{pm}$ model (the lowest frequency is $91.0 \mathrm{~cm}^{-1}$ ), Scheme 2 .

Table 1 gives the computational results and comparisons to experiment for deuterated derivatives of $\mathbf{1}, \mathbf{2}, \mathbf{4}$, and $\mathbf{5}$. Five different KIEs of endo-2-norbornyl brosylate (5-OBs) can be determined with excellent accuracy in the gas phase when $\mathbf{5}-\mathbf{O H}_{2}{ }^{+} \mathbf{T S}$ is used (entry TS in Table 1). Both normal and inverse KIEs are modelled correctly with only little overestimation. Accordingly, there are no surprises with the $210 \mathrm{pm}$ model of $\mathbf{5}$. While the calculated $\alpha$-effect in 5$\mathbf{O H}_{2}{ }^{+} \mathbf{2} \mathbf{e x}$ and the $\beta$-effect in the doubly deuterated 5-
Fig. 2. Gas-phase structures of $\mathbf{4}-\mathbf{O H}_{2}{ }^{+}$with the $\mathrm{C}-\mathrm{O}$ distance at 210 and $310 \mathrm{pm}$. See text for the highlighted bond.
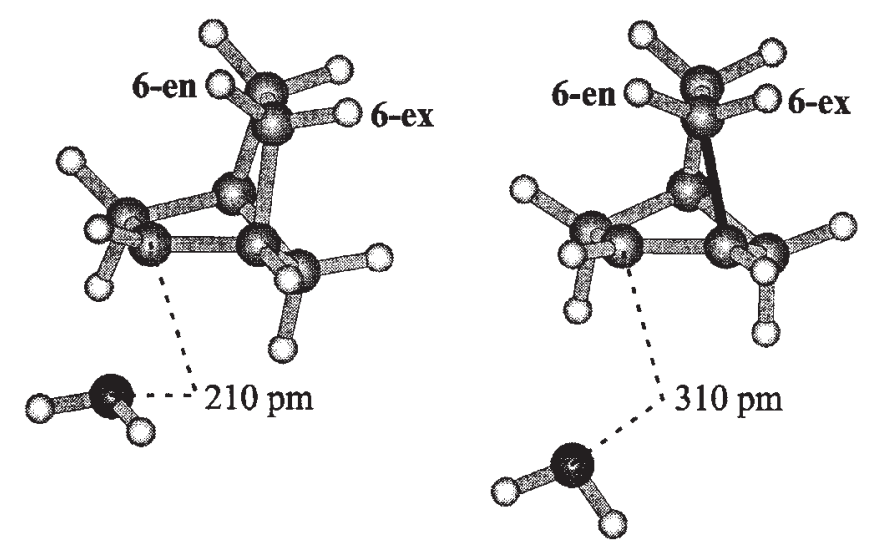

$\mathbf{O H}_{2}{ }^{+}$3en3ex are slightly too small, as expected due to the $210 \mathbf{~ p m}$ distance, which is shorter than the one in $\mathbf{5 - \mathbf { O H } _ { 2 } + \mathbf { T S }}$ (Fig. 1), the experimentally observed absence of a $\gamma$-effect in 5-OBs6ex and 5-OBs5ex6ex is confirmed computationally, as is the modest inverse $\gamma$-effect in 5-OBs6en. The situation is more complicated for exo-2-norbornyl brosylate (4-OBs). With 4- $\mathbf{O H}_{2}{ }^{+} \mathbf{T S}$, none of the four computed KIEs seems to show a particularly good agreement with experiment, the $\gamma$ effect in 4-OBs6ex and 4-OBs5ex6ex being overestimated and the $\beta$-effect in 4-OBs3en3ex underestimated. The calculated $\mathrm{KIE}$ in $\mathbf{4 - \mathbf { O H } _ { 2 }}{ }^{+}$6en seems to present the worst case. Using 4- $\mathbf{O H}_{2}{ }^{+} \mathbf{T S}$ it is much too small, and calculations on the $210 \mathrm{pm}$ model even predict the absence of any $\gamma$-KIE, whereas experimentally the largest KIE was found for the brosylate (11\%) (1). We repeated gas-phase calculations for 4- $\mathrm{OH}_{2}{ }^{+}$with $\mathrm{C}-\mathrm{O}$ distances of 180 and $310 \mathrm{pm}$. As expected, a $\mathrm{C}-\mathrm{O}$ distance of $180 \mathrm{pm}$ is too close to the optimized $\mathrm{C}-\mathrm{O}$ bond length of $163.7 \mathrm{pm}$ and therefore a poor

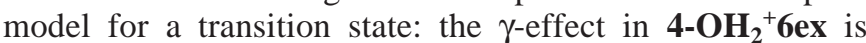
very small, there is no effect for $\mathbf{4 - \mathbf { O H } _ { 2 }}{ }^{+} \mathbf{6 e n}$. Going to a $\mathrm{C}-\mathrm{O}$ distance of $310 \mathrm{pm}$ gives rise to a significant $\gamma$-KIE in 4- $\mathbf{O H}_{2}{ }^{+} \mathbf{6 e n}$. These three TS models allow a step-by-step approach to the geometry change in the hydrocarbon moiety upon ionization and its effects. Figure 2 shows that the 2-norbornyl cation, which is definitely unsymmetrical at 210 pm (with distances $\mathrm{C}^{6}-\mathrm{C}^{1} 161.8 \mathrm{pm}$ and $\mathrm{C}^{6}-\mathrm{C}^{2} 230.3$ $\mathrm{pm})$, is closer to being symmetrical $\left(\mathrm{C}^{6}-\mathrm{C}^{1} 175.2 \mathrm{pm}\right.$ and $\mathrm{C}^{6}-\mathrm{C}^{2} 203.7 \mathrm{pm}$ ) at a water distance of $310 \mathrm{pm}$ where the distinction between endo and exo deuterium on $\mathrm{C}^{6}$ is fading with beginning internal return (the structures given in Fig. 2, with one highlighted bond for the $310 \mathrm{pm}$ model, represent the molecular graphs as determined in an atoms in molecules study (19)). This view finds support in the average KIE of 4- $\mathbf{O H}_{2}^{+} \mathbf{6 e x}$ and $\mathbf{4 -}-\mathbf{O H}_{2}^{+} \mathbf{6 e n}$, which equals 1.09 and so represents the experimental value (observed KIEs for 4OBs6ex and 4-OBs6en are identical within experimental error), and also in the early acetolysis study (4), which gives initial KIEs that are in accord with those computed, i.e., a significantly smaller value for 4-OBs6en: $1.149 \pm 0.016$ for 4-OBs6ex and $1.097 \pm 0.011$ for 4-OBs6en. For exo substrates anti-7-chloro 1-OBs and syn-7-chloro 2-OBs, we calculate exo KIEs that agree well with the observed ones whereas the endo KIEs, similar to $\mathbf{4 - \mathbf { O H } _ { 2 }}{ }^{+} \mathbf{6 e n}$, are too small. Yet unlike the case of $\mathbf{4 - O B s , ~ m a j o r ~ s o l v o l y s i s ~ p r o d u c t s ~ f o r ~}$ 
1-OBs6en (13\%) and 2-OBs6en (20\%) are the respective chloronortricyclenes formed through a 1,3 $(6,2)$-elimination with the endo deuterium being lost preferentially (close to $80 \%$ deuterium loss) (1), and it has been shown in a steadystate treatment of a modified Winstein ion-pair scheme (2) that (and how) the isotope effects for elimination from ion pairs can contribute to $k_{\mathrm{H}} / k_{\mathrm{D}}$.

In conclusion, deuterium secondary kinetic isotope effects are computed accurately at the Becke3LYP/6-31G(d,p) level of theory when solvolysis transition states are employed. Sources for observed KIEs can be explored and resolved with Becke3LYP calculations.

\section{Acknowledgments}

We gratefully acknowledge the grant of cpu time on a CRAY T90 vector computer in the HLRZ Supercomputing Center at the Research Center Jülich, the usage of the IBM SP2 computer at Queen's University granted under the auspices of an IBM Canada - Queen's University collaborative project, as well as the usage of the SGI computing installation in the Geochemistry Labs at McMaster funded by the Natural Sciences and Engineering Research Council of Canada (NSERC). We thank Ms. O. Donini for assistance with operational aspects of parallel Gaussian 94 and NSERC for financial support.

\section{References}

1. N.H. Werstiuk, G. Timmins, and F.P. Cappelli. Can. J. Chem. 58, 1738 (1980).

2. N.H. Werstiuk. Can. J. Chem. 53, 26 (1975).

3. B.L. Murr, A. Nickon, T.D. Swartz, and N.H. Werstiuk. J. Am. Chem. Soc. 89, 1730 (1967).

4. J.M. Jerkunica, S. Borčić, and D.E. Sunko. J. Am. Chem. Soc. 89, 1732 (1967)

5. (a) D.A. Singleton, S.R. Merrigan, J. Liu, and K.N. Houk. J. Am. Chem. Soc. 119, 3385 (1997); (b) B.R. Beno, K.N. Houk, and D.A. Singleton. J. Am. Chem. Soc. 118, 9984 (1996); (c) M.M. Davidson, J.M. Guest, J.S. Craw, I.H. Hillier, and M.A. Vincent. J. Chem. Soc. Perkin Trans. 2, 1395 (1997); (d) P. Czyryca and P. Paneth. J. Org. Chem. 62, 7305 (1997)

6. M.J. Frisch, G.W. Trucks, H.B. Schlegel, P.M.W. Gill, B.G. Johnson, M.A. Robb, J.R. Cheeseman, T. Keith, G.A.
Petersson, J.A. Montgomery, K. Raghavachari, M.A. Al-Laham, V.G. Zakrzewski, J.V. Ortiz, J.B. Foresman, C.Y. Peng, P.Y. Ayala, W. Chen, M.W. Wong, J.L. Andres, E.S. Replogle, R. Gomperts, R.L. Martin, D.J. Fox, J.S. Binkley, D.J. Defrees, J. Baker, J.P. Stewart, M. Head-Gordon, C. Gonzalez, and J.A. Pople. Gaussian 94, Revision B.3. Gaussian, Inc., Pittsburgh, Pa. 1995.

7. (a) S. Sieber, P.v.R. Schleyer, H. Vančik, M. Mesić, and D.E. Sunko. Angew. Chem. Int. Ed. Engl. 32, 1604 (1993); (b) P.v.R. Schleyer and S. Sieber. Angew. Chem. Int. Ed. Engl. 32, 1606 (1993).

8. P.R. Schreiner, P.v.R. Schleyer, and H.F. Schaefer III. J. Org. Chem. 62, 4216 (1997).

9. A.D. Becke. J. Chem. Phys. 98, 5648 (1993); C. Lee, W. Yang, and R.G. Parr. Phys. Rev. B: Condens. Matter, 37, 785 (1988).

10. (a) H.M. Muchall, N.H. Werstiuk, J. Ma, T.T. Tidwell, and K. Sung. Can. J. Chem. 75, 1851 (1997); (b) H.M. Muchall, N.H. Werstiuk, and B. Choudhury. Can. J. Chem. 76, 221 (1998); (c) N.H. Werstiuk, H.M. Muchall, C.D. Roy, J. Ma, and R.S. Brown. Can. J. Chem. 76, 672 (1998); (d) N.H. Werstiuk, H.M. Muchall, J. Ma, and M.T.H. Liu. Can. J. Chem. 76, 1162 (1998); (e) H.M. Muchall, N.H. Werstiuk, J.L. Pitters, and M.S. Workentin. Tetrahedron. In press; $(f)$ H.M. Muchall, N.H. Werstiuk, and J. Lessard. J. Mol. Struct. (Theochem). In press.

11. J.B. Foresman and A. Frisch. Exploring chemistry with electronic structure methods. 2nd ed. Gaussian, Inc., Pittsburgh, Pa. 1996.

12. J.O. Stoffer and J.D. Christen. J. Am. Chem. Soc. 92, 3190 (1970).

13. D.E. Sunko and S. Borčić. Isotope effects in chemical reactions. ACS Monograph 167. Edited by C.J. Collins and N.S. Bowman. Van Nostrand Reinhold Company, New York. 1970.

14. S. Borčić, V. Belanić-Lipovac, and D.E. Sunko. Croat. Chem. Acta, 33, 35 (1961).

15. C.C. Lee and E.W.C. Wong. J. Am. Chem. Soc. 86, 2752 (1964).

16. J.M. Jerkunica, S. Borčić, and D.E. Sunko. Chem. Commun. 1302 (1967).

17. R.F.W. Bader. Atoms in molecules. A quantum theory. Clarendon Press, Oxford. 1990.

18. (a) M.J.S. Dewar and A.P. Marchand. Ann. Rev. Phys. Chem. 16, 321 (1965); (b) M.J.S. Dewar and K.M. Merz, Jr. J. Am. Chem. Soc. 108, 5634 (1986).

19. N.H. Werstiuk and H.M. Muchall. J. Mol. Struct. (Theochem). In press. 